Research Paper

\title{
Preoperative plateletcrit is a Prognostic Biomarker for Survival in Patients with Non-Small Cell Lung Cancer
}

\author{
Joon Young Hur ${ }^{1}$, Ha Yeon Lee², Hye Jung Chang², Cheon Woong Choi³, Dae Hyun Kim4, Wan Kyu Eo ${ }^{3 凶}$ \\ 1. Division of Hematology and Oncology, Department of Medicine, Samsung Medical Center, Sungkyunkwan University School of Medicine, Seoul, Korea. \\ 2. Division of Hematology and Oncology, Department of Internal Medicine, National Medical Center, Seoul, Korea. \\ 3. Department of Internal Medicine, Kyung Hee University Hospital at Gangdong, Seoul, Korea \\ 4. Department of Thoracic Surgery, Kyung Hee University Hospital at Gangdong, Seoul, Korea \\ $\square$ Corresponding author: Wan Kyu Eo, Department of Internal Medicine, Kyung Hee University Hospital at Gangdong, \#892 Dongnam-ro, Gangdong-gu, \\ Seoul, 05278, Korea. Telephone: 82-10-3553-6211. E-mail : wankyu.eo@gmail.com.
}

( ) The author(s). This is an open access article distributed under the terms of the Creative Commons Attribution License (https://creativecommons.org/licenses/by/4.0/). See http://ivyspring.com/terms for full terms and conditions.

Received: 2019.10.12; Accepted: 2020.02.06; Published: 2020.02.25

\begin{abstract}
Objectives: Several factors associated with the prognosis of patients with NSCLC have been reported in the literature; however, most of these factors cannot be examined preoperatively. In this study, the clinical utility of platelet parameters in patients with NSCLC who underwent curative resection was evaluated.

Materials and Methods: A retrospective study on patients with NSCLC who underwent curative resection from July 2006 to September 2016 was conducted. The Cox proportional hazard regression model was applied to evaluate the variables that demonstrated effects on disease-free and overall survival (DFS and OS).

Results: A total of 116 patients with NSCLC were analyzed. There were 15 patients with plateletcrit greater than $0.2755 \%$, and 101 patients whose plateletcrit was $0.2755 \%$ or lower. Multivariate analysis identified plateletcrit higher than $0.2755 \%$ (hazard ratio $[\mathrm{HR}]=4.18,95 \%$ confidence interval $[\mathrm{Cl}]=1.54-11.34, \mathrm{P}=0.004)$, patient age of 65 years or more $(\mathrm{HR}=4.02,95 \% \mathrm{Cl}$ $=1.67-9.66, \mathrm{P}=0.001)$, and stage II or IIIA disease $(\mathrm{HR}=2.95,95 \% \mathrm{Cl}=1.26-6.87, \mathrm{P}=0.012)$ as independent factors for OS that predicted a poor prognosis. Multivariate analysis identified plateletcrit higher than $0.2755 \%(\mathrm{HR}=4.07,95 \% \mathrm{Cl}=1.52-10.94, \mathrm{P}=0.005)$, stage II or IIIA disease $(\mathrm{HR}=5.38,95 \% \mathrm{Cl}=2.71-10.66, \mathrm{P}<0.001)$ and non-adenocarcinoma $(\mathrm{HR}=1.92,95 \% \mathrm{Cl}=$ 1.02-3.59, $\mathrm{P}=0.040$ ) as independent prognostic factors for DFS that predicted a poor prognosis.
\end{abstract}

Conclusion: Our results suggest a potential role of preoperative plateletcrit as an independent prognostic marker for patients with resectable NSCLC.

Key words: plateletcrit; non small cell lung cancer; mean platelet volume.

\section{Introduction}

Lung cancer is the leading cause of cancer-related death in men and women in the United States [1] and South Korea [2]. Lung cancers are classified into small cell or non-small cell types, for the purpose of treatment. Non-small cell lung cancers (NSCLCs) account for approximately $80 \%$ of all lung cancers [3]. Most lung cancers (57\%) are diagnosed at advanced stages, because early disease is typically asymptomatic; only $16 \%$ of cases are diagnosed early in the disease process [4]. For the treatment of stage I and II NSCLC, most patients (69\%) undergo surgery, and about $25 \%$ of these also receive additional chemotherapy or radiation therapy, or both [4]. On the other hand, most patients with stage III and IV NSCLC (53\%) receive chemotherapy, with or without radiation therapy [4].

In patients with advanced or relapsed lung cancers, testing for the presence of epidermal growth 
factor receptor (EGFR)-sensitizing mutations [5] and the status of anaplastic lymphoma kinase (ALK) gene rearrangements prior to the use of tyrosine kinase inhibitors (TKIs) for therapy has substantially improved survival outcomes [6]. Recently, programmed death ligand 1 (PD-L1) testing has been included in the evaluation of primary NSCLC, in accordance with the National Comprehensive Cancer Network guidelines (2017 version). Immunotherapeutic drugs that act by targeting the programmed cell death receptors on $\mathrm{T}$ cells prolong the disease-free periods and overall survival (OS) in patients with advanced NSCLC [7]; further studies on these aspects in patients with early disease are ongoing [8]. Overexpression of $\mathrm{p} 53$ protein is prognostic for poorer survival and is predictive of differentially greater survival benefits from receiving adjuvant chemotherapy [9]. Several factors associated with the prognosis of patients with NSCLC have been reported in the literature; however, most of these factors cannot be examined preoperatively [3] .

In terms of laboratory factors, an increased systemic inflammatory response (SIR) has been demonstrated to be associated with a poor prognosis; in particular, a selective combination of C-reactive protein (CRP) and albumin (termed the modified Glasgow Prognostic Score, mGPS) has been shown to be of prognostic value in lung cancer [10]. With respect to hematologic factors, a combination of the neutrophil-lymphocyte ratio (NLR) and the platelet-lymphocyte ratio (PLR) has been used to divide patients with advanced NSCLC into three different prognostic groups, prior to the initiation of treatment [11].

The presence of thrombocytosis can predict prognosis in many types of cancer, such as esophageal cancer [12] , gastric cancer [13], colorectal cancer [14], and NSCLC [15]. Mean platelet volume (MPV) is an important indicator of platelet activation [16]. Recent studies have revealed that MPV levels are abnormal in patients with NSCLC [16]. It has been suggested that platelet count and its parameters, including plateletcrit, platelet distribution width (PDW), and MPV might be useful in combination with other acute phase reactants to define inflammation activation [17]. Platelet parameters can be obtained using routine hematology analyzers during peripheral blood sampling. In comparison with other prognostic factors, platelet parameters are less costly and therefore can be used more extensively [16]. To the best of our knowledge, few platelet parameters have been studied in cases of operable NSCLC, with the exception of platelet count and MPV. Therefore, the aim of the present study was to evaluate the clinical utility of platelet parameters in patients with NSCLC who underwent curative resection.

\section{Methods}

\section{Patient selection and study design}

A retrospective study was conducted on patients with NSCLC who underwent curative resection at the Kyung Hee University Hospital at Gangdong from July 2006 to September 2016. The study was approved by the Institutional Review Board of the Kyung Hee University Hospital at Gangdong (KHNMC 2017-01004-001). Written informed consent was waived for this study, because of its retrospective nature. The electronic medical records of all patients with NSCLC who underwent curative resection were reviewed. The inclusion criteria were as follows: (i) patients who were diagnosed with primary NSCLC by expert pathologists, according to the 2015 World Health Organization (WHO) classification of lung tumors [18], and staged as I to IIIA, according to the 7th edition of the TNM Classification (Union for International Cancer Control); (ii) histological types of NSCLC, such as squamous cell carcinoma, adenocarcinoma, large cell carcinoma, or adenosquamous carcinoma; and (iii) patients who underwent pneumonectomy, bilobectomy, lobectomy, or segmentectomy. The exclusion criteria for patients were as follows: (i) patients who underwent preoperative chemotherapy or radiotherapy; (ii) presence of histologically confirmed neuroendocrine tumor, sarcomatoid carcinoma, small cell lung cancer (SCLC), or salivary gland tumor; (iii) history of liver cirrhosis (LC) or immune thrombocytopenic purpura (ITP); (iv) use of medications that may affect hemostasis; and (v) patients with stage IIIB or IV disease. A total of 228 patients were initially enrolled, and 112 patients were excluded for the following reasons: (i) 41 patients underwent wedge resection for diagnosis or palliation therapy; (ii) 12 patients had been diagnosed with neuroendocrine tumor; (iii) 8 patients were diagnosed with sarcomatoid carcinoma, 6 with SCLC, and 1 with a salivary gland tumor; (iv) 5 patients had undergone preoperative chemotherapy or radiotherapy; (v) 2 patients had LC and one had ITP; (vi) 32 patients were using aspirin, clopidogrel, cilostazol, or sarpogrelate; and (vii) 2 patients had stage IIIB disease and 2 had stage IV. Finally, 116 patients with NSCLC were included in the present study (supplementary figure 1). Computed tomography (CT) scans of the chest, abdomen, and pelvis, and positron emission tomography (PET)/CT scans were used for staging. Magnetic resonance imaging (MRI) or CT scans were used to evaluate potential brain metastases. 


\section{Clinical variables}

Records of clinical variables, such as sex, age, smoking status, histological type, histological grading, TNM stage, ECOG performance status, adjuvant therapy, maximal tumor dimension, and surgical resection type, were collected and analyzed. All laboratory data for patients were recorded before the patients underwent surgery. Data on blood tests obtained on the closest date to the day of surgery, within 7 days prior to surgery, were selected. Leukocytosis was defined as WBC counts higher than $11,000 / \mu \mathrm{L}$. The diagnoses of anemia in men and women were based on hemoglobin levels less than 13 $\mathrm{g} / \mathrm{dL}$ and $12 \mathrm{~g} / \mathrm{dL}$, respectively. The platelet parameters considered were platelet counts (PLT), MPV, PDW, and plateletcrit [19]. Thrombocytosis was defined as platelet counts greater than $300 \times 10^{3} / \mu \mathrm{L}$.

\section{Optimum cut-off values}

The prognostic impact of a continuous variable (e.g. plateletcrit) on the survival of patients with NSCLC was evaluated with maximally selected rank statistics using $\mathrm{R}$ (maxstat package) software. The recommended cut-off values of plateletcrit was $0.2755 \%$ for survivals in patients with NSCLC. To determine the most favorable cut-off values for clinical variables, receiver operating characteristic (ROC) curve analysis was used. The recommended cut-off values were as follows: MPV, $8.6 \mathrm{fL}$ (sensitivity $90.3 \%$, specificity $61.2 \%$ ); area under the curve (AUC), 0.77 . For the maximal tumor dimension, the cut-off value was $2.9 \mathrm{~cm}$ (sensitivity $83.9 \%$, specificity $52.9 \%$ ); AUC, 0.715 .

\section{Statistical analysis}

$\mathrm{R}$ software (version 3.2.3, $\mathrm{R}$ for Statistics Computing, Vienna, Austria) was used for statistical processing. OS was defined as the period from the date of surgery to the date of death. Data were represented as means \pm standard deviations. Baseline clinical characteristics were compared using chi-squared tests for categorical values, and t-tests for continuous variables. The Cox proportional hazard regression model was used to evaluate the variables that demonstrated effects on OS; multivariate analysis was performed on these variables, with a $P$ value of less than 0.05. The Cox proportional hazard regression model with backward elimination was used to validate the independent prognostic factors. Survival differences were analyzed using Kaplan-Meier analysis and the log-rank test. P values less than 0.05 were considered statistically significant.

\section{Results}

\section{Baseline clinical characteristics of patients}

A total of 116 patients with NSCLC were analyzed (supplementary figure 1). These patients were divided into two groups, based on their plateletcrit values; 15 patients had plateletcrit values greater than $0.2755 \%$, and 101 had plateletcrit values of $0.2755 \%$ or less. Sex, age, histologic grading, smoking history, adjuvant therapy, TNM stage, maximal tumor dimension, Eastern Cooperative Oncology Group (ECOG) performance status, white blood cell (WBC) counts, hemoglobin counts, and MPV did not significantly differ between the two groups (Table 1). There was a significant increase in platelets in the patients with plateletcrit greater than $0.2755 \%$. As shown in Table 1, 57 (49.1\%) patients were aged 65 years or older, and $73(62.9 \%)$ of the 116 patients were men. The most common histological subtype of NSCLC was adenocarcinoma, followed by squamous cell carcinoma, adenosquamous cell carcinoma, and large cell carcinoma. A total of 69 $(59.5 \%)$ patients were categorized as having stage I disease, and $47(40.5 \%)$ as stage II or IIIA. The ECOG performance status of all patients was either $0(54.3 \%)$ or $1(45.7 \%)$. Of the 116 patients, $47(40.5 \%)$ had never smoked, and $42(36.2 \%)$ had received adjuvant therapy, such as chemotherapy, radiotherapy, or chemoradiotherapy. Commonly used chemotherapy regimens were cisplatin plus vinorelbine $(n=17)$, and carboplatin plus paclitaxel $(n=14)$. The most common surgical modality was lobectomy, which was performed on 94 patients $(81.0 \%)$, followed by segmentectomy, which was performed on 14 patients $(12.1 \%)$.

\section{Relationship between platelet parameters and OS}

Significant differences were observed in the Kaplan-Meier survival curves for OS between the groups showing normal platelet counts and thrombocytosis. As shown in Table 2, the 5-year OS rates in the groups showing thrombocytosis and normal platelet counts were 0.526 and 0.810 , respectively $(\mathrm{P}=0.031)$. There were also significant differences in the overall survival curves with respect to plateletcrit (Figure 1). The 5-year OS rate was 0.899 in the group with MPV greater than $8.6 \mathrm{fL}$, and 0.683 in the group with MPV of $8.6 \mathrm{fL}$ or less $(\mathrm{P}=0.039)$. Additionally, the 5-year OS rates in the groups with plateletcrit of $0.2755 \%$ or less and greater than $0.2755 \%$ were reported as 0.761 and 0.485 , respectively $(\mathrm{P}=0.039)$. 
Table 1. Baseline characteristics of NSCLC patients.

\begin{tabular}{|c|c|c|c|c|}
\hline Variables & $\begin{array}{l}\text { Plateletcrit } \\
\leq 0.2755 \% \\
(n=101)\end{array}$ & $\begin{array}{l}\text { Plateletcrit } \\
>0.2755 \% \\
(\mathrm{n}=15)\end{array}$ & $\begin{array}{l}\text { Total } \\
(n=116)\end{array}$ & $P$ \\
\hline Sex & & & & 0.544 \\
\hline Female & $39(38.6 \%)$ & $4(26.7 \%)$ & $43(37.1 \%)$ & \\
\hline Male & $62(61.4 \%)$ & $11(73.3 \%)$ & $73(62.9 \%)$ & \\
\hline Age (years) & & & & 0.630 \\
\hline$<65$ & $50(49.5 \%)$ & $9(60.0 \%)$ & $59(50.9 \%)$ & \\
\hline$\geq 65$ & $51(50.5 \%)$ & $6(40.0 \%)$ & $57(49.1 \%)$ & \\
\hline Histologic type & & & & 0.009 \\
\hline $\mathrm{ADC}$ & $72(71.3 \%)$ & $5(33.3 \%)$ & $77(66.4 \%)$ & \\
\hline Non-ADC & $29(28.7 \%)$ & $10(66.7 \%)$ & $39(33.6 \%)$ & \\
\hline Histologic grade & & & & 0.680 \\
\hline G1/G2 & $79(78.2 \%)$ & $13(86.7 \%)$ & $92(79.3 \%)$ & \\
\hline G3 & $22(21.8 \%)$ & $2(13.3 \%)$ & $24(20.7 \%)$ & \\
\hline Smoking & & & & 0.745 \\
\hline Never & $42(41.6 \%)$ & $5(33.3 \%)$ & $47(40.5 \%)$ & \\
\hline Past or current & $59(58.4 \%)$ & $10(66.7 \%)$ & $69(59.5 \%)$ & \\
\hline ECOG PS & & & & 0.719 \\
\hline 0 & $56(55.4 \%)$ & $7(46.7 \%)$ & $63(54.3 \%)$ & \\
\hline 1 & $45(44.6 \%)$ & $8(53.3 \%)$ & $53(45.7 \%)$ & \\
\hline Adjuvant therapy & & & & 0.968 \\
\hline No & $65(64.4 \%)$ & $9(60.0 \%)$ & $74(63.8 \%)$ & \\
\hline Yes & $36(35.6 \%)$ & $6(40.0 \%)$ & $42(36.2 \%)$ & \\
\hline $\begin{array}{l}\text { Maximal } \\
\text { dimension } \\
\text { of tumor }(\mathrm{cm})\end{array}$ & & & & 1.000 \\
\hline$<2.9$ & $43(42.6 \%)$ & $6(40.0 \%)$ & $49(42.2 \%)$ & \\
\hline$\geq 2.9$ & $58(57.4 \%)$ & $9(60.0 \%)$ & $67(57.8 \%)$ & \\
\hline Stage & & & & 0.325 \\
\hline I & $60(59.4 \%)$ & $9(60.0 \%)$ & $69(59.5 \%)$ & \\
\hline II or IIIA & $41(40.6 \%)$ & $6(40.0 \%)$ & $47(40.5 \%)$ & \\
\hline Leukocytosis & & & & 0.136 \\
\hline No & $99(98.0 \%)$ & $13(86.7 \%)$ & $112(96.6 \%)$ & \\
\hline Yes & $2(2.0 \%)$ & $2(13.3 \%)$ & $4(3.4 \%)$ & \\
\hline Anemia & & & & 0.340 \\
\hline No & $64(63.4 \%)$ & $7(46.7 \%)$ & $71(61.2 \%)$ & \\
\hline Yes & $37(36.6 \%)$ & $8(53.3 \%)$ & $45(38.8 \%)$ & \\
\hline Thrombocytosis & & & & $<0.001$ \\
\hline No & $86(85.1 \%)$ & $3(20.0 \%)$ & $89(76.7 \%)$ & \\
\hline Yes & $15(14.9 \%)$ & $12(80.0 \%)$ & $27(23.3 \%)$ & \\
\hline MPV (fL) & & & & 0.774 \\
\hline$\leq 8.6$ & $55(54.5 \%)$ & $7(46.7 \%)$ & $62(53.4 \%)$ & \\
\hline$>8.6$ & $46(45.5 \%)$ & $8(53.3 \%)$ & $54(46.6 \%)$ & \\
\hline Operation & & & & 0.272 \\
\hline Bilobectomy & $3(2.8 \%)$ & $2(13.3 \%)$ & $5(4.3 \%)$ & \\
\hline Lobectomy & $83(82.2 \%)$ & $11(73.3 \%)$ & $94(81.0 \%)$ & \\
\hline Pneumonectomy & $2(2.0 \%)$ & $1(6.7 \%)$ & $3(2.6 \%)$ & \\
\hline Segmentectomy & $13(12.9 \%)$ & $1(6.7 \%)$ & $14(12.1 \%)$ & \\
\hline
\end{tabular}

ADC: adenocarcinoma; ECOG PS: eastern cooperative oncology group performance status; WBC: white blood cell; $\mathrm{Hb}$ : hemoglobin; MPV: mean platelet volume.

\section{Prognostic factors associated with OS}

Univariate and multivariate analyses for OS are shown in Table 3. Univariate analyses identified male sex $(P=0.020)$, age 65 years or greater $(P=0.011)$, history of smoking $(\mathrm{P}=0.012)$, non-adenocarcinoma histological type $(\mathrm{P}<0.001)$, ECOG performance status of $1(\mathrm{P}=0.008)$, maximal tumor dimension greater than $2.9 \mathrm{~cm}(\mathrm{P}=0.009)$, stage II or IIIA disease $(P=0.022)$, leukocytosis $(P=0.003)$, thrombocytosis $(P$ $=0.035)$ and plateletcrit greater than $0.2755 \%(\mathrm{P}=$ 0.046 ) as factors for OS that predicted poor prognosis. Multivariate analysis identified plateletcrit higher than $0.2755 \%$ (hazard ratio $[\mathrm{HR}]=4.18,95 \%$ confidence interval $[\mathrm{CI}]=1.54-11.34, \mathrm{P}=0.004)$, patient age of 65 years or more $(\mathrm{HR}=4.02,95 \% \mathrm{CI}=$ $1.67-9.66, \mathrm{P}=0.001)$, and stage II or IIIA disease ( $\mathrm{HR}=$ $2.95,95 \% \mathrm{CI}=1.26-6.87, \mathrm{P}=0.012)$ as independent factors for OS that predicted a poor prognosis.

\section{Relationship between platelet parameters and DFS}

Significant differences were observed in the Kaplan-Meier survival curves for DFS with respect to plateletcrit values, as shown in Figure 2. As shown in Table 2, the 5-year DFS rate was 0.541 in the group of patients with plateletcrit of $0.2755 \%$ or lower, compared to 0.491 in the group with plateletcrit greater than $0.2755 \%(P=0.023)$. However, there were no significant differences in the DFS rates with respect to MPV and platelet counts.

Table 2. Analysis for 5 year overall survival and 5 year disease free survival.

\begin{tabular}{|c|c|c|c|c|}
\hline Variables & 5YR OS & $P$ & 5YR DFS & $P$ \\
\hline Sex & & 0.015 & & 0.355 \\
\hline Female & 0.902 & & 0.643 & \\
\hline Male & 0.631 & & 0.473 & \\
\hline Age (years) & & 0.008 & & 0.600 \\
\hline$<65$ & 0.845 & & 0.555 & \\
\hline$\geq 65$ & 0.619 & & 0.513 & \\
\hline Histologic type & & $<0.001$ & & $<0.001$ \\
\hline $\mathrm{ADC}$ & 0.858 & & 0.651 & \\
\hline Non-ADC & 0.500 & & 0.336 & \\
\hline Histologic grade & & 0.412 & & 0.030 \\
\hline $\mathrm{G} 1 / \mathrm{G} 2$ & 0.765 & & 0.576 & \\
\hline G3 & 0.535 & & 0.357 & \\
\hline Smoking & & 0.008 & & 0.093 \\
\hline Never & 0.912 & & 0.688 & \\
\hline Past or current & 0.606 & & 0.427 & \\
\hline ECOG PS & & 0.005 & & 0.002 \\
\hline 0 & 0.831 & & 0.631 & \\
\hline 1 & 0.619 & & 0.431 & \\
\hline $\begin{array}{l}\text { Maximal dimension } \\
\text { of tumor }(\mathrm{cm})\end{array}$ & & 0.005 & & 0.001 \\
\hline$<2.9$ & 0.940 & & 0.756 & \\
\hline$\geq 2.9$ & 0.593 & & 0.388 & \\
\hline Stage & & 0.019 & & $<0.001$ \\
\hline I & 0.908 & & 0.834 & \\
\hline II or IIIA & 0.530 & & 0.201 & \\
\hline Leukocytosis & & $<0.001$ & & 0.011 \\
\hline No & 0.756 & & 0.553 & \\
\hline Yes & 0 & & 0 & \\
\hline Anemia & & 0.354 & & 0.097 \\
\hline No & 0.748 & & 0.599 & \\
\hline Yes & 0.699 & & 0.450 & \\
\hline Thrombocytosis & & 0.031 & & 0.191 \\
\hline No & 0.810 & & 0.559 & \\
\hline Yes & 0.526 & & 0.463 & \\
\hline MPV (fL) & & 0.039 & & 0.437 \\
\hline$>8.6$ & 0.899 & & 0.537 & \\
\hline$\leq 8.6$ & 0.683 & & 0.524 & \\
\hline Plateletcrit (\%) & & 0.039 & & 0.023 \\
\hline$\leq 0.2755$ & 0.761 & & 0.541 & \\
\hline$>0.2755$ & 0.485 & & 0.491 & \\
\hline
\end{tabular}




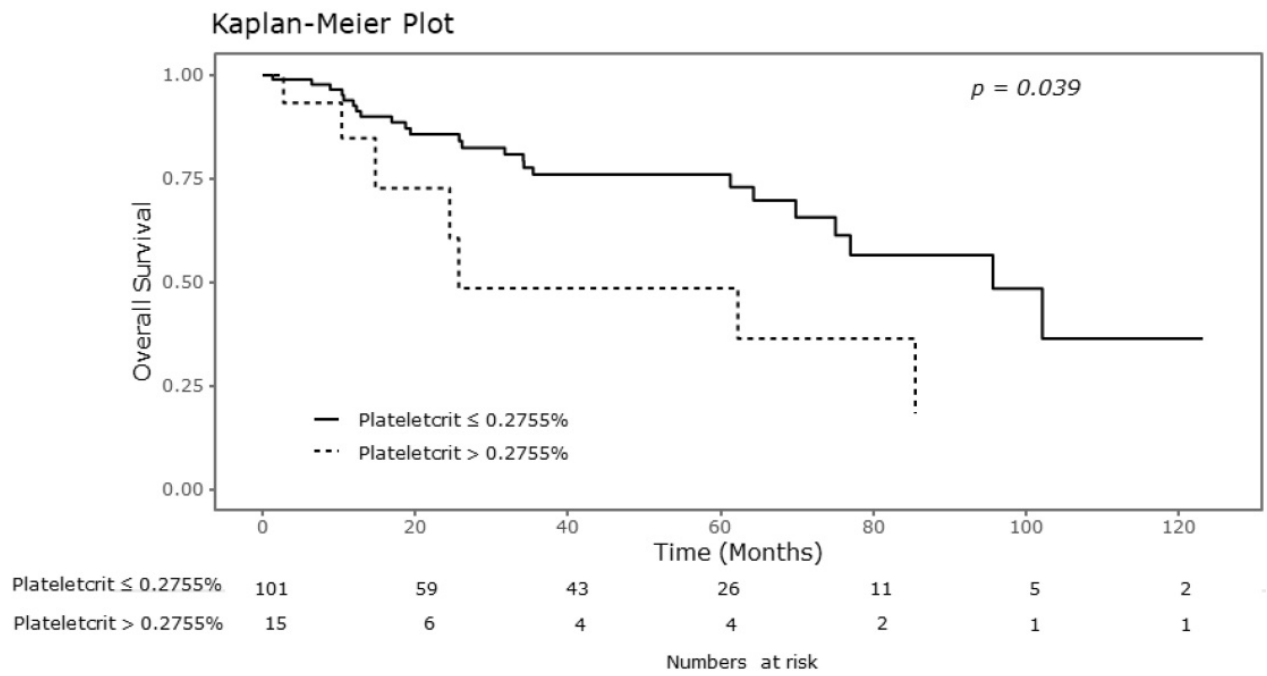

Figure 1. Kaplan-Meier curve for overall survival according to plateletcrit.

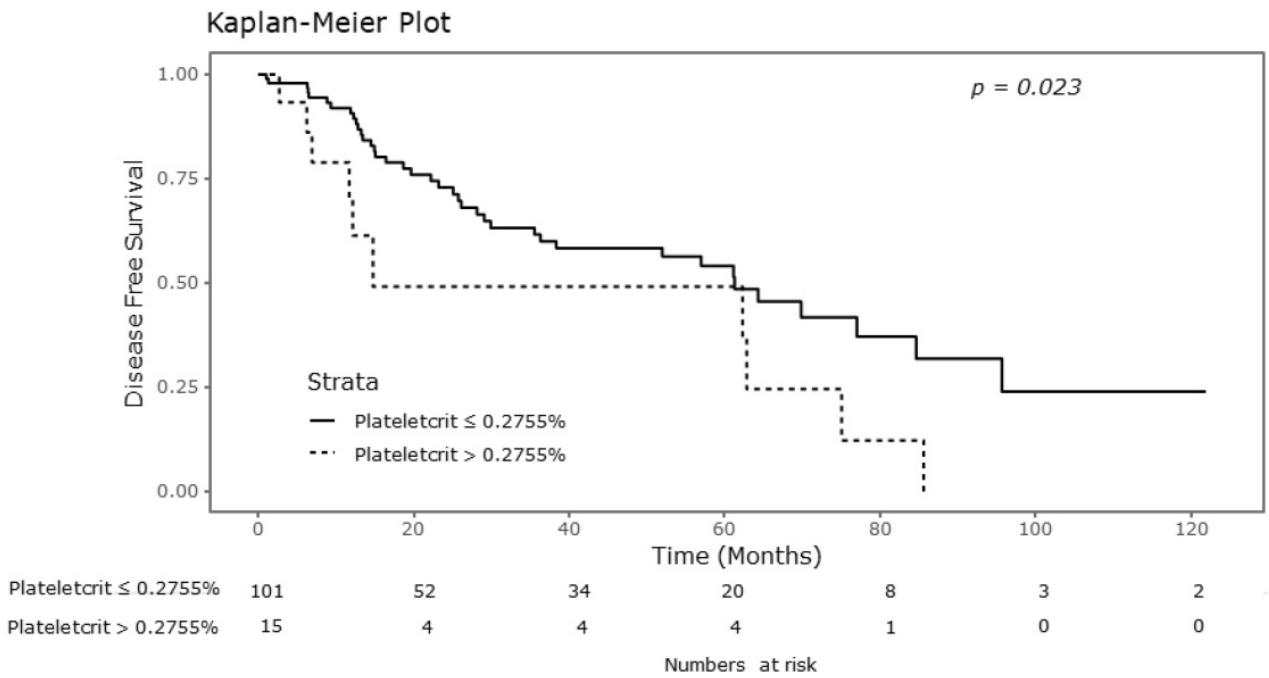

Figure 2. Kaplan-Meier curve for disease free survival according to plateletcrit.

Table 3. Analysis of prognostic factors for overall survival.

\begin{tabular}{|c|c|c|c|c|c|c|}
\hline \multirow[b]{2}{*}{ Variables } & \multicolumn{3}{|c|}{ Univariate } & \multicolumn{3}{|c|}{ Multivariate } \\
\hline & HR & $95 \% \mathrm{CI}$ & $P$ & HR & $95 \% \mathrm{CI}$ & $P$ \\
\hline Sex : Female vs. male & 3.12 & $1.19-8.15$ & 0.020 & - & - & - \\
\hline Age (years): $<65$ vs. $\geq 65$ & 2.83 & $1.26-6.33$ & 0.011 & 4.02 & $1.67-9.66$ & 0.001 \\
\hline $\begin{array}{l}\text { Histologic type : ADC vs. } \\
\text { non-ADC }\end{array}$ & 3.93 & $1.88-8.23$ & $<0.001$ & - & - & - \\
\hline $\begin{array}{l}\text { Histologic grading : G1 or } \\
\text { G2 vs. G3 }\end{array}$ & 1.46 & $0.59-3.60$ & 0.414 & - & - & - \\
\hline $\begin{array}{l}\text { Smoking : never vs. past } \\
\text { or current }\end{array}$ & 3.14 & $1.29-7.67$ & 0.012 & - & - & - \\
\hline ECOG PS : 0 vs. 1 & 2.82 & $1.32-6.03$ & 0.008 & - & - & - \\
\hline $\begin{array}{l}\text { Maximal dimension of } \\
\text { tumor }(\mathrm{cm}):<2.9 \text { vs. } \geq \\
2.9\end{array}$ & 3.58 & $1.37-9.36$ & 0.009 & - & - & - \\
\hline Stage : I vs. II or IIIA & 2.32 & $1.13-4.80$ & 0.022 & 2.95 & $1.26-6.87$ & 0.012 \\
\hline Leukocytosis : No vs. Yes & 6.50 & $1.89-22.46$ & 0.003 & - & - & - \\
\hline Anemia : No vs. Yes & 1.40 & $0.68-2.87$ & 0.356 & - & - & - \\
\hline $\begin{array}{l}\text { Thrombocytosis : No vs. } \\
\text { Yes }\end{array}$ & 2.18 & $1.06-4.51$ & 0.035 & - & - & - \\
\hline $\operatorname{MPV}(\mathrm{fL}):>8.6$ vs. $\leq 8.6$ & 0.30 & $0.90-1.01$ & 0.052 & - & - & - \\
\hline $\begin{array}{l}\text { Plateletcrit }(\%): \leq 0.2755 \\
\text { vs. }>0.2755\end{array}$ & 2.37 & $1.01-5.54$ & 0.046 & 4.18 & $1.54-11.34$ & 0.004 \\
\hline
\end{tabular}

\section{Prognostic factors associated with DFS}

Univariate and multivariate analyses for DFS are shown in Table 4. Univariate analysis identified non-adenocarcinoma histological type $(\mathrm{P}=0.001)$, histological grade $3(\mathrm{P}=0.034)$, ECOG performance status of $1(\mathrm{P}=0.003)$, maximal tumor dimension of more than $2.9 \mathrm{~cm}(\mathrm{P}=0.002)$, stage II or IIIA disease ( $\mathrm{P}$ $<0.001)$, leukocytosis $(\mathrm{P}=0.020)$, and plateletcrit greater than $0.2755 \%(\mathrm{P}=0.028)$ as factors for DFS that predicted poor prognosis. Multivariate analysis identified plateletcrit higher than $0.2755 \%(\mathrm{HR}=4.07$, $95 \% \mathrm{CI}=1.52-10.94, \mathrm{P}=0.005)$, stage II or IIIA disease $(\mathrm{HR}=5.38,95 \% \mathrm{CI}=2.71-10.66, \mathrm{P}<0.001)$ and non-adenocarcinoma $(\mathrm{HR}=1.92,95 \% \mathrm{CI}=1.02-3.59, \mathrm{P}$ $=0.040)$ as independent prognostic factors for DFS that predicted a poor prognosis. 
Table 4. Analysis of prognostic factors for disease free survival.

\begin{tabular}{|c|c|c|c|c|c|c|}
\hline \multirow[b]{2}{*}{ Variables } & \multicolumn{3}{|c|}{ Univariate } & \multicolumn{3}{|c|}{ Multivariate } \\
\hline & HR & $95 \% \mathrm{Cl}$ & $P$ & HR & $95 \% \mathrm{CI}$ & $P$ \\
\hline Sex : Female vs. male & 1.35 & $0.73-2.49$ & 0.346 & - & - & - \\
\hline Age : $<65$ vs. $\geq 65$ & 1.16 & $0.66-2.06$ & 0.601 & - & - & - \\
\hline $\begin{array}{l}\text { Histoligic type : ADC } \\
\text { vs. non-ADC }\end{array}$ & 2.55 & $1.45-4.48$ & 0.001 & 1.92 & $1.02-3.59$ & 0.040 \\
\hline $\begin{array}{l}\text { Histologic grading: } \\
\text { G1 or G2 vs. G3 }\end{array}$ & 2.11 & $1.06-4.23$ & 0.034 & - & - & - \\
\hline $\begin{array}{l}\text { Smoking : never vs. } \\
\text { past or current }\end{array}$ & 1.67 & $0.91-3.04$ & 0.097 & - & - & - \\
\hline ECOG PS : 0 vs. 1 & 2.45 & $1.36-4.43$ & 0.003 & - & - & - \\
\hline $\begin{array}{l}\text { Maximal dimension of } \\
\text { tumor }(\mathrm{cm}):<2.9 \text { vs. } \geq \\
2.9\end{array}$ & 2.84 & $1.45-5.58$ & 0.002 & - & - & - \\
\hline Stage : I vs. II or IIIA & 4.56 & $2.48-8.38$ & $<0.001$ & 5.38 & $2.71-10.66$ & $<0.001$ \\
\hline $\begin{array}{l}\text { Leukocytosis : No vs. } \\
\text { Yes }\end{array}$ & 4.12 & $1.25-13.61$ & 0.020 & - & - & - \\
\hline Anemia : No vs. Yes & 1.60 & $0.91-2.81$ & 0.101 & - & - & - \\
\hline $\begin{array}{l}\text { Thrombocytosis : No } \\
\text { vs. Yes }\end{array}$ & 1.48 & $0.82-2.66$ & 0.194 & - & - & - \\
\hline $\begin{array}{l}\text { MPV (fL) : }>8.6 \text { vs. } \leq \\
8.6\end{array}$ & 0.76 & $0.39-1.51$ & 0.438 & - & - & - \\
\hline $\begin{array}{l}\text { Plateletcrit (\%) : } \leq \\
0.2755 \text { vs. }>0.2755\end{array}$ & 2.20 & $1.09-4.45$ & 0.028 & 4.07 & $1.52-10.94$ & 0.005 \\
\hline
\end{tabular}

\section{Discussion}

Tumor-related humoral factors, such as granulocyte colony-stimulating factor (GCSF), interleukin-1 (IL-1), and interleukin-6 (IL-6), stimulate platelet production [20]. Platelets release various cytokines, including vascular endothelial growth factor (VEGF) and platelet-derived growth factor (PDGF), which have significant roles in regulating angiogenesis [15]. Experimental evidence suggests that platelets actively promote cancer progression through a variety of mechanisms, including protecting cancer cells from immune surveillance, negotiating the arrest of cancer cells in the microvasculature, and stimulating angiogenesis $[15$, 21]. Decreased platelet surface expression of P-selectin and activated glycoprotein (GP)IIb/IIIa, in vivo and in response to protease-activated receptor (PAR)-1, PAR-4, and GP VI activation, has been associated with poor OS in patients with cancer [22].

The results of the present study indicate that preoperative plateletcrit may be used as a biomarker to predict outcomes in patients with NSCLC who undergo curative resections; this conclusion is based on the significant differences in DFS and OS observed in these patients, based on their plateletcrit values. It is expected that plateletcrit greater than $0.2755 \%$ would be associated with increased risks of death and disease recurrence. To the best of our knowledge, this study is the first to analyze the relationship between plateletcrit and prognosis in patients with NSCLC.

Plateletcrit refers to the volume occupied by the platelets in the blood [23] and is a marker of total platelet mass. The plateletcrit is determined by the formula platelet count times MPV divided by $10^{4}$, and the normal range for plateletcrit is $0.22-0.24 \%$ [23]. In a study of patients with papillary thyroid carcinoma (PTC), the plateletcrit ranges were $0.24 \pm 0.05$ in the group with PTC and $0.17 \pm 0.02$ in the control group, with a significant difference between the two groups $(P<0.01)$ [24]. In the present study, the plateletcrit range was $0.0870-0.3802 \%$ and the cut-off value was $0.2755 \%$ according to maximally selected rank statistics using $\mathrm{R}$ (maxstat package) software. However, data investigating the importance of plateletcrit among platelet parameters are limited [25].

The reason for the association between elevated plateletcrit and worse outcomes for patients with NSCLC remains unknown. However, plateletcrit is also related to platelet activation [17]. Plateletcrit has been used as a predictive marker in the discrimination of autoimmune gastritis [26], and it is an important predictor for saphenous vein graft disease (SVGD) [27]. Plateletcrit may act as a sensitive and specific biomarker for determining disease activity in Crohn's disease, especially in those with high-sensitivity CRP (hs-CRP) lower than $10.0 \mathrm{mg} / \mathrm{L}$ [28]. Significantly, an association between high plateletcrit and poor OS in patients with locally advanced pancreatic adenocarcinoma has been reported [17]. In addition, plateletcrit was shown to be consistently higher in a group of patients with epithelial ovarian cancer (EOC) than in the benign tumor and healthy groups, and the trend toward higher levels of platelet parameters reflected enhancement of bone marrow hematopoietic activity [29].

The present study has several limitations. First, as this is the first report on the clinical utility of plateletcrit in patients with lung cancer, the optimal cut-off values for plateletcrit are yet to be defined. Therefore, the results of this study need to be interpreted with caution. Second, among the platelet parameters, the PDW was not analyzed because data pertaining to PDW could not be obtained. The PDW indicates volume variability in the size of platelets, and is a valuable marker for platelet activity; thus, in further studies, the PDW must be included in the analysis. In conclusion, our results suggest a potential role of preoperative plateletcrit as an independent prognostic marker for patients with resectable NSCLC. However, the results obtained from our study are hypothesis generating, and should be confirmed with larger studies. In addition, internal and external validation will be needed in future prospective studies to rule out chance findings. 


\section{Abbreviations}

ADC: adenocarcinoma; ECOG PS: eastern cooperative oncology group performance status; WBC: white blood cell; $\mathrm{Hb}$ : hemoglobin; MPV: mean platelet volume; OS: overall survival; DFS: disease free survival; HR: hazard ratio; $\mathrm{CI}$ : confidence interval; NSCLC: Non-small cell lung cancer; SCLC: small cell lung cancer; ITP: immune thrombocytopenic purpura; EGFR: epidermal growth factor receptor; ALK: anaplastic lymphoma kinase; TKI: tyrosine kinase inhibitors; PD-L1: programmed death ligand 1; SIR: systemic inflammatory response; CRP: C-reactive protein; mGPS: modified Glasgow Prognostic Score; NLR: neutrophil-lymphocyte ratio; PLR: platelet-lymphocyte ratio; PDW: platelet distribution width; ROC: receiver operating characteristic; AUC: area under the curve.

\section{Supplementary Material}

Supplementary Figure 1.

http://www.jcancer.org/v11p2800s1.pdf

\section{Authors' Contributions}

Joon Young Hur and Wan Kyu Eo contributed to the study conception and design. Joon Young Hur, Ha Yeon Lee and Hye Jung Chang contributed to revision of the manuscript. Joon Young Hur contributed to acquisition of data and drafting of manuscript. Dae Hyun Kim and Chun Woong Choi analyzed the manuscript. All authors read and approved the final manuscript.

\section{Competing Interests}

The authors have declared that no competing interest exists.

\section{References}

1. Siegel RL, Miller KD, Jemal A. Cancer statistics, 2016. CA: a cancer journal for clinicians. 2016; 66: 7-30.

2. Jung K-W, Won Y-J, Kong H-J, Oh C-M, Cho H, Lee DH, et al. Cancer statistics in Korea: incidence, mortality, survival, and prevalence in 2012. Cancer research and treatment : official journal of Korean Cancer Association. 2015; 47: 127-41

3. Zhang H, Zhang L, Zhu K, Shi B, Yin Y, Zhu J, et al. Prognostic significance of combination of preoperative platelet count and neutrophil-lymphocyte ratio (COP-NLR) in patients with non-small cell lung cancer: based on a large cohort study. PloS one. 2015; 10: e0126496.

4. Miller KD, Siegel RL, Lin CC, Mariotto AB, Kramer JL, Rowland JH, et al. Cancer treatment and survivorship statistics, 2016. CA: a cancer journal for clinicians. 2016; 66: 271-89.

5. Han SW, Kim TY, Hwang PG, Jeong S, Kim J, Choi IS, et al. Predictive and prognostic impact of epidermal growth factor receptor mutation in non-small-cell lung cancer patients treated with gefitinib. Journal of clinical oncology : official journal of the American Society of Clinical Oncology. 2005; 23: 2493-501.

6. Sim SH, Beom SH, Ahn YO, Keam B, Kim TM, Lee $\mathrm{SH}$, et al. Pretreatment neutrophil-lymphocyte ratio is not a significant prognostic factor in epidermal growth factor receptor-mutant non-small cell lung cancer patients treated with tyrosine kinase inhibitors. Thoracic cancer. 2016; 7: 161-6.

7. Reck M, Rodriguez-Abreu D, Robinson AG, Hui R, Csoszi T, Fulop A, et al. Pembrolizumab versus chemotherapy for PD-L1-positive non-small-cell lung cancer. The New England journal of medicine. 2016; 375: 1823-33.

8. Melosky B, Chu Q, Juergens R, Leighl N, McLeod D, Hirsh V. Pointed progress in second-line advanced non-small-cell lung cancer: the rapidly evolving field of checkpoint inhibition. Journal of clinical oncology : official journal of the American Society of Clinical Oncology. 2016; 34: 1676-88.

9. Tsao MS, Aviel-Ronen S, Ding K, Lau D, Liu N, Sakurada A, et al. Prognostic and predictive importance of p53 and RAS for adjuvant chemotherapy in non small-cell lung cancer. Journal of clinical oncology : official journal of the American Society of Clinical Oncology. 2007; 25: 5240-7.

10. Proctor MJ, Morrison DS, Talwar D, Balmer SM, O'Reilly DS, Foulis AK, et al. An inflammation-based prognostic score (mGPS) predicts cancer survival independent of tumour site: a Glasgow Inflammation Outcome Study. British journal of cancer. 2011; 104: 726-34.

11. Wu G, Yao Y, Bai C, Zeng J, Shi D, Gu X, et al. Combination of platelet to lymphocyte ratio and neutrophil to lymphocyte ratio is a useful prognostic factor in advanced non-small cell lung cancer patients. Thoracic cancer. 2015; 6: 275-87.

12. Shimada H, Oohira G, Okazumi S, Matsubara H, Nabeya Y, Hayashi H, et al. Thrombocytosis associated with poor prognosis in patients with esophageal carcinoma. Journal of the American College of Surgeons. 2004; 198: 737-41.

13. Ikeda M, Furukawa $H$, Imamura $H$, Shimizu J, Ishida $H$, Masutani S, et al. Poor prognosis associated with thrombocytosis in patients with gastric cancer. Annals of surgical oncology. 2002; 9: 287-91.

14. Wang H, Gao J, Bai M, Liu R, Li H, Deng T, et al. The pretreatment platelet and plasma fibrinogen level correlate with tumor progression and metastasis in patients with pancreatic cancer. Platelets. 2014; 25: 382-7.

15. Yu D, Liu B, Zhang L, Du K. Platelet count predicts prognosis in operable non-small cell lung cancer. Experimental and therapeutic medicine. 2013; 5: 1351-4

16. Gao L, Zhang H, Zhang B, Zhang L, Wang C. Prognostic value of combination of preoperative platelet count and mean platelet volume in patients with resectable non-small cell lung cancer. Oncotarget. 2017; 8: 15632-41.

17. Wang L, Sheng L, Liu P. The independent association of platelet parameters with overall survival in pancreatic adenocarcinoma receiving intensity-modulated radiation therapy. International journal of clinical and experimental medicine. 2015; 8: 21215-21.

18. Travis WD, Brambilla E, Nicholson AG, Yatabe Y, Austin JHM, Beasley MB, et al. The 2015 World Health Organization Classification of Lung Tumors: Impact of Genetic, Clinical and Radiologic Advances Since the 2004 Classification. Journal of thoracic oncology : official publication of the International Association for the Study of Lung Cancer. 2015; 10: 1243-60.

19. Oncel M, Kiyici A, Oncel M, Sunam GS, Sahin E, Adam B. Evaluation of Platelet Indices in Lung Cancer Patients. Asian Pacific journal of cancer prevention : APJCP. 2015; 16: 7599-602.

20. Kim M, Chang H, Yang HC, Kim YJ, Lee CT, Lee JH, et al. Preoperative thrombocytosis is a significant unfavorable prognostic factor for patients with resectable non-small cell lung cancer. World journal of surgical oncology. 2014; 12 : 37.

21. Stone RL, Nick AM, McNeish IA, Balkwill F, Han HD, Bottsford-Miller J, et al. Paraneoplastic thrombocytosis in ovarian cancer. The New England journal of medicine. 2012; 366: 610-8.

22. Riedl J, Kaider A, Marosi C, Prager GW, Eichelberger B, Assinger A, et al. Decreased platelet reactivity in patients with cancer is associated with high risk of venous thromboembolism and poor prognosis. Thrombosis and haemostasis. 2017; 117: 90-8.

23. Budak YU, Polat M, Huysal K. The use of platelet indices, plateletcrit, mean platelet volume and platelet distribution width in emergency non-traumatic abdominal surgery: a systematic review. Biochemia medica. 2016; 26: 178-93.

24. Dincel O, Bayraktar C. Evaluation of platelet indices as a useful marker in papillary thyroid carcinoma. Bratislavske lekarske listy. 2017; 118: 153-5.

25. Ifran A, Hasimi A, Kaptan K, Nevruz O, Beyan C, Erbil K. Evaluation of platelet parameters in healthy apheresis donors using the ADVIA 120. Transfusion and apheresis science : official journal of the World Apheresis Association : official journal of the European Society for Haemapheresis. 2005; 33: 87-90.

26. Tuzun A, Keskin O, Yakut M, Kalkan C, Soykan I. The predictive value of mean platelet volume, plateletcrit and red cell distribution width in the differentiation of autoimmune gastritis patients with and without type I gastric carcinoid tumors. Platelets. 2014; 25: 363-6. 
27. Akpinar I, Sayin MR, Gursoy YC, Karabag T, Kucuk E, Buyukuysal MC, et al. Plateletcrit. A platelet marker associated with saphenous vein graft disease. Herz. 2014; 39: 142-8.

28. Tang J, Gao X, Zhi M, Zhou HM, Zhang M, Chen HW, et al. Plateletcrit: a sensitive biomarker for evaluating disease activity in Crohn's disease with low hs-CRP. Journal of digestive diseases. 2015; 16: 118-24.

29. Ma X, Wang Y, Sheng H, Tian W, Qi Z, Teng F, et al. Prognostic significance of thrombocytosis, platelet parameters and aggregation rates in epithelial ovarian cancer. The journal of obstetrics and gynaecology research. 2014; 40: 178-83. 